\title{
Nocardia pseudobrasiliensis sp. nov., a New Species of Nocardia Which Groups Bacterial Strains Previously Identified as Nocardia brasiliensis and Associated with Invasive Diseases
}

\author{
RAYMOND RUIMY, ${ }^{1 *}$ PHILIPPE RIEGEL, ${ }^{2}$ ARNAUD CARLOTTI, ${ }^{3}$ PATRICK BOIRON, ${ }^{4}$ \\ GILLES BERNARDIN, ${ }^{5}$ HENRI MONTEIL, ${ }^{2}$ RICHARD J. WALLACE, JR., ${ }^{6}$ \\ AND RICHARD CHRISTEN ${ }^{1}$
}

Centre National de la Recherche Scientifique and Université Paris 6, Station Zoologique, 06230 Villefranche sur Mer, ${ }^{1}$

Laboratoire de Bactériologie de la Faculté de Médecine, F-67000 Strasbourg, ${ }^{2}$ Laboratoire de Mycologie

Fondamentale, Faculté de Pharmacie, Université Claude Bernard-Lyon I, 69373 Lyon Cedex 08, ${ }^{3}$

Unité de Mycologie, Institut Pasteur, 75724 Paris Cedex $15,{ }^{4}$ and Service de Réanimation Médicale, Hopital de l'ARCHET, 06200 Nice, ${ }^{5}$ France, and Department of

Microbiology, University of Texas Health Center

at Tyler, Tyler, Texas $75710^{6}$

\begin{abstract}
We studied five strains of a new Nocardia taxon recently identified among Nocardia brasiliensis strains associated with invasive diseases (R. J. Wallace, Jr., B. A. Brown, Z. Blacklock, R. Ulrich, K. Jost, J. M. Brown, M. M. McNeil, G. Onyi, V. A. Steingrube, and J. Gibson, J. Clin. Microbiol. 33:1528-1533, 1995) to determine their taxonomic status. Several characteristics of these organisms, including the presence of chemotype IV cell walls, nocardomycolic acids, a predominant menaquinone similar to that of Nocardia asteroides ATCC $19247^{\mathrm{T}}$ ( $\mathrm{T}=$ type strain), and $\mathrm{G}+\mathrm{C}$ contents ranging from 67 to $68 \mathrm{~mol} \%$, are characteristics of the genus Nocardia. Phylogenies based on small-subunit ribosomal DNA sequences clearly confirmed that all five strains belong to the genus Nocardia and occur on a single branch that is clearly distinct from $N$. brasiliensis. This branch forms a clade with Nocardia vaccinii, Nocardia nova, Nocardia otitidiscaviarum, and Nocardia seriolae. The five new strains exhibited high levels of DNA relatedness with each other, as determined by DNA-DNA hybridization experiments (S1 nuclease procedure), but not with $N$. brasiliensis strains or with strains of the four phylogenetically related Nocardia species mentioned above. The five new strains differ from $N$. brasiliensis in the following characteristics: mycolic acid pattern, decomposition of adenine, nitrate reduction, and antimicrobial agent susceptibilities. Therefore, we propose that these strains belong to a new species, Nocardia pseudobrasiliensis. The type strain is strain ATCC 51512, which was isolated from a leg abscess on a patient suffering from ulcerative colitis.
\end{abstract}

After its description in Bergey's Manual of Systematic Bacteriology (10) and The Prokaryotes (8), the genus Nocardia became a more well-defined taxon as a consequence of the recent transfer of Nocardia amarae to the genus Gordona $(9,16,20)$ and the exclusion of Nocardia pinensis (3). The genus Nocardia now includes the following species: Nocardia asteroides, Nocardia carnea, Nocardia brasiliensis, Nocardia farcinica, Nocardia brevicatena, Nocardia otitidiscaviarum, Nocardia nova, Nocardia seriolae, Nocardia transvalensis, and Nocardia vaccinii. Most of these species cause infectious diseases in humans and animals. The majority of human nocardioses $(1,2,4)$ are caused by members of the $N$. asteroides complex, which includes three species ( $N$. farcinica, $N$. nova, and $N$. asteroides sensu stricto) that cannot be distinguished from each other easily $(26,27)$.

In contrast to $N$. asteroides sensu stricto, the other humanpathogenic Nocardia species, including $N$. brasiliensis, $N$. otitidiscaviarum, and $N$. transvalensis, are usually considered homogeneous (8). However, Wallace et al. (25) described a new taxon for some $N$. brasiliensis strains on the basis of taxonomic criteria, as well as clinical criteria. Taxonomically, this new taxon differs from $N$. brasiliensis in the following characteristics: decomposition of adenine, reduction of nitrate, susceptibility to ciprofloxacin and/or clarithromycin, and resistance to minocycline. Medically, members of this taxon generally in-

\footnotetext{
* Corresponding author. Phone: (33) 937637 84. Fax: (33) 937637 93. Electronic mail address: ruimy@ccrv.obs-vlfr.fr.
}

duce noncutaneous nocardioses, such as a pulmonary nocardiosis, a central nervous system nocardiosis, or a systemic nocardiosis, while $N$. brasiliensis sensu stricto is isolated mainly from cutaneous sites (25).

To establish more precisely the taxonomic status of the new taxon and to distinguish it from $N$. brasiliensis, we studied four of the strains used by Wallace et al. (25) and one strain isolated in France in 1992 from a patient with fatal systemic nocardiosis. The phylogenetic positions of these strains were determined precisely by comparing small-subunit ribosomal DNA (rDNA) sequences. We then determined the genomic DNA base compositions, as well as the levels of DNA relatedness among the isolates and the levels of DNA relatedness with other Nocardia species. On the basis of the data which we obtained, we propose that a new species, Nocardia pseudobrasiliensis, should be established.

\section{MATERIALS AND METHODS}

Strains, media, and growth conditions. We studied one strain (strain CIP 104598) that was isolated in the Laboratory of Bacteriology of Nice (Nice University Hospital, Nice, France) and was submitted for identification to the National Reference Center for Mycosis and Antifungal Agents, Pasteur Institute, Paris, France. The other four strains which we used (strains ATCC 51511 [= CIP 104599], ATCC 51512 ${ }^{\mathrm{T}}$ [= CIP 104600] [T = type strain], N249 [= CIP 104601], and N649 [= CIP 104602]) were included in a previous study (25). All of these strains were isolated from human clinical sources (Table 1).

All of the strains were stored either freeze-dried or on Bennett agar (13) covered with paraffin oil and were subcultured at $32^{\circ} \mathrm{C}$ on fresh Bennett agar or blood agar. 
TABLE 1. Levels of DNA relatedness between N. pseudobrasiliensis and other Nocardia species

\begin{tabular}{|c|c|c|c|c|}
\hline \multirow{2}{*}{ Strain $^{a}$} & \multirow[t]{2}{*}{ Source } & \multirow{2}{*}{$\begin{array}{c}\mathrm{G}+\mathrm{C} \text { content } \\
(\mathrm{mol} \%)\end{array}$} & \multicolumn{2}{|c|}{$\begin{array}{l}\text { DNA relatedness to strain } \\
\text { ATCC } 51512^{\mathrm{T}}\end{array}$} \\
\hline & & & $\%^{b}$ & $\Delta T_{m}\left({ }^{\circ} \mathrm{C}\right)$ \\
\hline N. pseudobrasiliensis ATCC 51511 (= CIP 104599) & Abscess on buttocks & & 80 & 0.5 \\
\hline N. pseudobrasiliensis ATCC $51512^{\mathrm{T}}\left(=\mathrm{CIP} 104600^{\mathrm{T}}\right)$ & Leg abscess & 67.1 & 100 & 0 \\
\hline N. pseudobrasiliensis N249 (= CIP 104601) & Brain abscess & 67.4 & 88 & 3.0 \\
\hline N. pseudobrasiliensis N649 (= CIP 104602) & Sputum & & 90 & 0.5 \\
\hline N. pseudobrasiliensis CIP 104598 & Blood & 68.4 & 60 & 4.5 \\
\hline N. brasiliensis ATCC $19296^{\mathrm{T}}$ & & & 11 & \\
\hline N. nova ATCC $33726^{\mathrm{T}}$ & & & 12 & \\
\hline N. otitidiscaviarum ATCC $14629^{\mathrm{T}}$ & & & 11 & \\
\hline N. seriolae ATCC $43993^{\mathrm{T}}$ & & & 7 & \\
\hline N. vaccinii ATCC $11092^{\mathrm{T}}$ & & & 14 & \\
\hline
\end{tabular}

a ATCC, American Type Culture Collection, Rockville, Md.; CIP, Collection Institut Pasteur, Paris, France.

${ }^{b}$ Level of relative binding at $65^{\circ} \mathrm{C}$.

Biochemical characteristics and susceptibility tests. Biochemical and susceptibility tests were performed with isolate CIP 104598 by using previously described methods (25).

Cell wall analysis. Cells were hydrolyzed and menaquinones were extracted and purified by using the procedure of Page et al. (17). The purified menaquinones were separated by reverse-phase high-performance liquid chromatography (HPLC) with a Nucleosil C18 $(5 \mu \mathrm{m})$ column $(25 \mathrm{~cm}$ by $4.5 \mathrm{~mm}$ [internal diameter]) and were eluted with methanol-isopropyl ether $(3: 1, \mathrm{vol} / \mathrm{vol})$, as described by Tamaoka et al. (24). The menaquinones were detected with a UV monitor (Waters 990 photodiode array detector; Millipore Corp., Milford, Mass.) at the emission wavelength ( 230 to $240 \mathrm{~nm}$ ) and were identified by thei $R_{f}$ values and their UV spectra. Standard menaquinones (MK-7 to MK-12) were kindly provided by Hoffman-la-Roche, Ltd., Basel, Switzerland, while di- and tetrahydrogenated menaquinones were prepared from reference strains (5) Menaquinones from $N$. asteroides ATCC $19247^{\mathrm{T}}$ were also included in the HPLC pattern comparison.

The mycolic acid $p$-bromophenacyl ester patterns of isolate CIP 104598 were determined by the HPLC method as modified by Jost and Dunbar (14).

DNA-DNA hybridization. The cultures used for DNA extraction were grown for $72 \mathrm{~h}$ at $30^{\circ} \mathrm{C}$ in $500 \mathrm{ml}$ of brain heart broth (bioMérieux). Cells were harvested by centrifugation, and the purity of each preparation was checked by growing it on sheep blood-containing Trypticase soy agar for $72 \mathrm{~h}$ at $30^{\circ} \mathrm{C}$. The DNA was extracted as described previously (18), except that $10 \mathrm{mg}$ of proteinase K (Sigma) and $20 \mathrm{mg}$ of sodium dodecyl sulfate were added to each $1 \mathrm{ml}$ of lysozymetreated bacteria. The purity of each preparation was ascertained by determining the ratio of $A_{280}$ to $A_{260}$ and the ratio of $A_{230}$ to $A_{260}$. Hybridization experiments in which labeled DNA and fragmented DNA preparations were used were performed at $65^{\circ} \mathrm{C}$ for $16 \mathrm{~h}$ in $0.42 \mathrm{M} \mathrm{NaCl}$ by using the S1 nuclease-trichloroacetic acid method $(11,18)$. The denaturation temperature (the temperature at which $50 \%$ of the reassociated DNA was hydrolyzed by S1 nuclease) was determined in $0.2 \mathrm{M} \mathrm{NaCl}$ by the method of Crosa et al. (6). $\Delta T_{m}$ was the difference between the denaturation temperature of a homoduplex (in a homologous reaction) and the denaturation temperature of a heteroduplex (in a heterologous reaction). The DNA similarity results for each pair given below are the means of the values obtained in three separate DNA hybridization experiments.

DNA base composition. The guanine-plus-cytosine $(\mathrm{G}+\mathrm{C})$ contents of strain ATCC $51512^{\mathrm{T}}$, CIP 104598 , and N249 DNAs were determined by using a capillary electrophoresis method and the same DNA preparations that were used for the DNA-DNA hybridization experiments. After extraction and purification on cesium chloride gradients, the DNA was hydrolyzed by the DNase I-nuclease P1 method of Gehrke et al. (7). A Waters Quanta 4000 system (Millipore) was used, and data analysis was performed by using Waters Baseline 810 software (Millipore). The deoxynucleotides were separated by using a $16-\mathrm{kV}$ positive voltage and a fused-silica capillary column (total length, $54 \mathrm{~cm}$; inside diameter, $50 \mu \mathrm{m}$; distance between injection and detection parts, $47 \mathrm{~cm}$; Beckman Instruments Palo Alto, Calif.). Samples were loaded by hydrostatic injection $(10-\mathrm{cm}$ height for

TABLE 2. Similarity matrix based on small-subunit rDNA sequences

\begin{tabular}{|c|c|c|c|c|c|c|c|c|c|c|c|c|c|c|c|c|}
\hline \multirow[b]{2}{*}{ Strain } & \multirow[b]{2}{*}{$\begin{array}{l}\text { Nucleotide sequence } \\
\text { accession no. }\end{array}$} & \multicolumn{15}{|c|}{$\%$ Similarity ${ }^{a}$} \\
\hline & & 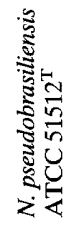 & 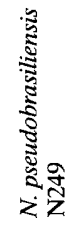 & 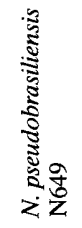 & 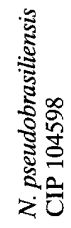 & 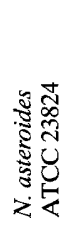 & 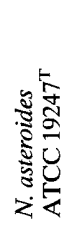 & 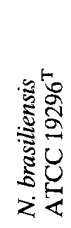 & 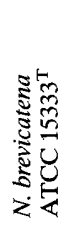 & 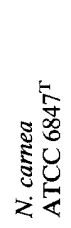 & 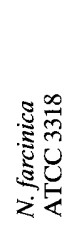 & 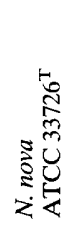 & 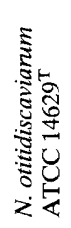 & 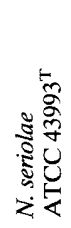 & 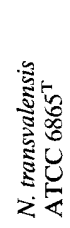 & 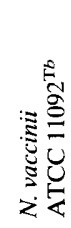 \\
\hline N. pseudobrasiliensis ATCC 51511 & $\mathrm{X} 84856$ & 99.9 & 99.4 & 100.0 & 99.5 & 97.9 & 97.4 & 96.9 & 97.6 & 96.9 & 96.2 & 98.2 & 97.9 & 96.7 & 96.8 & 96.8 \\
\hline N. pseudobrasiliensis ATCC $51512^{\mathrm{T}}$ & X84857 & & 99.5 & 99.9 & 99.5 & 97.8 & 97.3 & 96.9 & 97.6 & 96.9 & 96.1 & 98.1 & 98.0 & 96.8 & 96.7 & 96.7 \\
\hline N. pseudobrasiliensis $\mathrm{N} 249$ & X84854 & & & 99.4 & 99.5 & 97.3 & 97.3 & 96.9 & 97.3 & 96.9 & 96.2 & 98.0 & 98.2 & 97.0 & 96.7 & 96.5 \\
\hline N. pseudobrasiliensis N649 & $\mathrm{X} 84855$ & & & & 99.5 & 97.9 & 97.4 & 96.9 & 97.6 & 96.9 & 96.2 & 98.2 & 97.9 & 96.7 & 96.8 & 96.8 \\
\hline N. pseudobrasiliensis CIP 104598 & $\mathrm{X} 84852$ & & & & & 97.3 & 97.2 & 96.9 & 97.5 & 96.6 & 96.2 & 98.3 & 98.2 & 96.9 & 96.8 & 96.6 \\
\hline N. asteroides ATCC 23824 & $\mathrm{X} 84850$ & & & & & & 98.9 & 97.6 & 97.6 & 97.6 & 97.6 & 97.4 & 96.9 & 96.5 & 97.3 & 96.7 \\
\hline N. asteroides ATCC $19247^{\mathrm{T}}$ & $\mathrm{X} 84851$ & & & & & & & 97.9 & 98.2 & 97.9 & 98.2 & 97.2 & 97.0 & 96.3 & 97.9 & 96.6 \\
\hline N. brasiliensis ATCC $19296^{\mathrm{T}}$ & X80591 & & & & & & & & 96.6 & 96.6 & 98.0 & 96.4 & 96.1 & 95.8 & 97.4 & 95.6 \\
\hline N. brevicatena ATCC $15333^{\mathrm{T}}$ & $\mathrm{X} 80600$ & & & & & & & & & 97.9 & 96.6 & 97.3 & 97.2 & 96.9 & 97.0 & 97.5 \\
\hline N. carnea ATCC $6847^{\mathrm{T}}$ & $\mathrm{X} 80602$ & & & & & & & & & & 96.3 & 96.3 & 96.6 & 96.1 & 96.5 & 96.3 \\
\hline N. farcinica ATCC 3318 & X80595 & & & & & & & & & & & 96.2 & 96.0 & 95.3 & 97.9 & 96.3 \\
\hline N. nova ATCC $33726^{\mathrm{T}}$ & $\mathrm{X} 80593$ & & & & & & & & & & & & 98.5 & 97.4 & 97.2 & 97.9 \\
\hline N. otitidiscaviarum ATCC $14629^{\mathrm{T}}$ & X80599 & & & & & & & & & & & & & 98.0 & 96.8 & 97.4 \\
\hline N. seriolae ATCC $43993^{\mathrm{T}}$ & X80592 & & & & & & & & & & & & & & 95.7 & 97.0 \\
\hline N. transvalensis ATCC $6865^{\mathrm{T}}$ & $\mathrm{X} 80598$ & & & & & & & & & & & & & & & 96.6 \\
\hline
\end{tabular}

${ }^{a}$ Values were determined by using all nucleotides that were aligned without ambiguity (see the text).

${ }^{b}$ The nucleotide sequence accession number for $N$. vaccinii ATCC $11092^{\mathrm{T}}$ is X80597. 


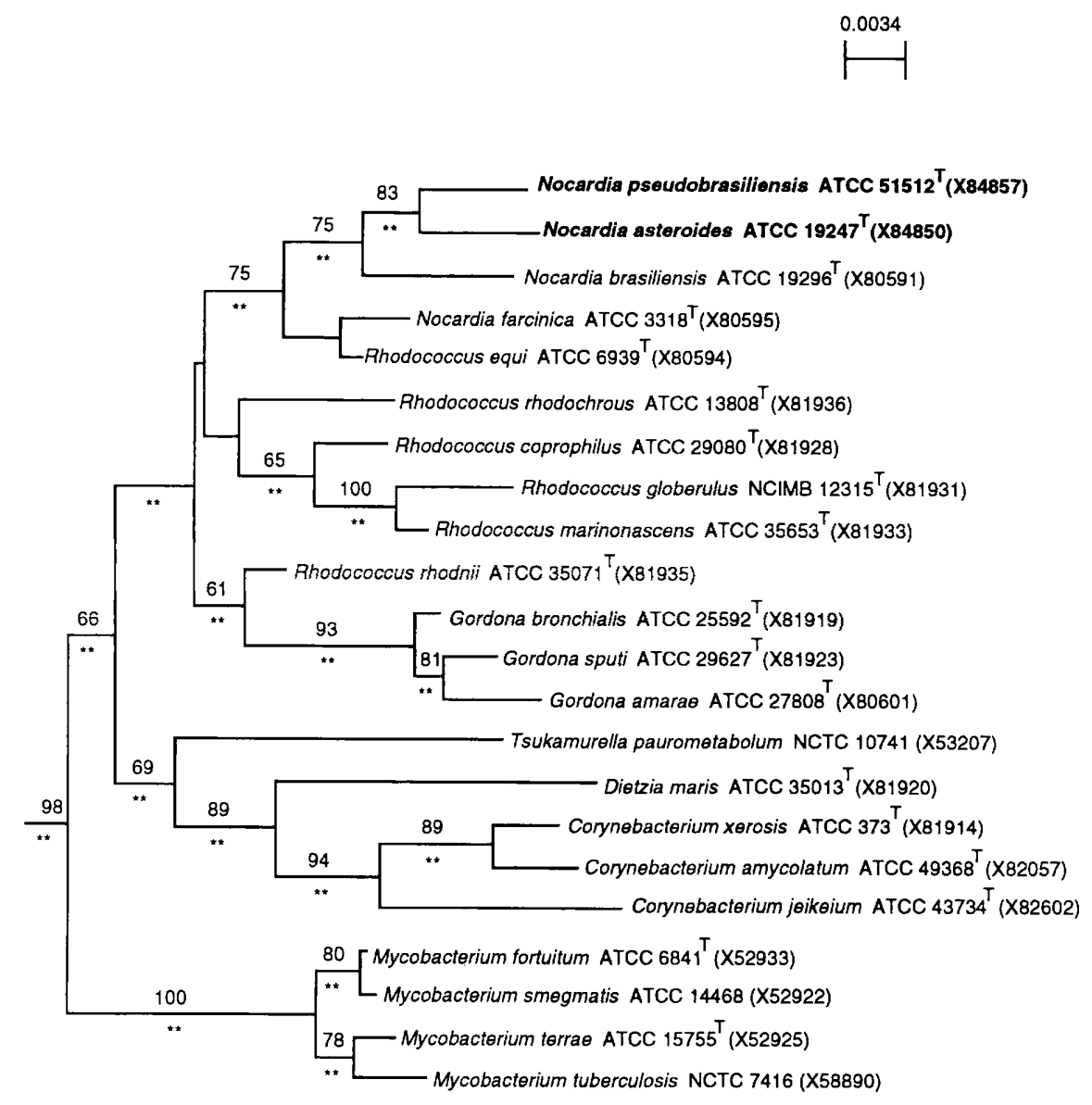

FIG. 1. Phylogenetic positions of Nocardia species within the CMN group (20). The topology shown is part of a tree obtained by a neighbor-joining method and summarizes the results of phylogenetic analyses in which three different methods were used. The outgroups used to root the tree were representatives of the different genera belonging to the family Pseudonocardiaceae, the genus Saccharothrix, and the genus Actinokineospora. The double asterisks indicate branches that were also identified by a maximum-likelihood method $(P<0.01)$. Values above the lines (expressed as percentages; only values greater than $50 \%$ are shown) indicate branches that were also found on the most parsimonious tree; these values indicate how the branches were supported by the bootstrap analysis results (heuristic search). Bar $=$ number of accumulated changes per nucleotide. The numbers in parentheses are nucleotide sequence accession numbers. The sequences of strains ATCC 51512 and ATCC $19247^{\mathrm{T}}$ were determined in this study. The other sequences were obtained from the EMBL database.

$40 \mathrm{~s}$ ) and were analyzed by UV detection at $254 \mathrm{~nm}$. The buffer used for electrophoresis was a $35 \mathrm{mM}$ sodium tetraborate solution adjusted to $\mathrm{pH} 9.45$. Between runs, the capillary column was washed with $0.1 \mathrm{M}$ sodium hydroxide for $3 \mathrm{~min}$ and distilled water for $3 \mathrm{~min}$ and then reconditioned with the running buffer for $2 \mathrm{~min}$. The amount of each of the four nucleotides was determined by using a calibration curve established with nucleotide standards ( 0 to $250 \mu \mathrm{mol} /$ liter; Sigma Chemical Co., St. Louis, Mo.). Phage lambda DNA (G+C content, $49.858 \mathrm{~mol} \%$ ) was used as a control to determine the accuracy of the method.

Small-subunit rDNA gene sequencing. A 100-ng portion of DNA was used in a PCR to amplify the small-subunit rDNA genes. A pair of primers corresponding to positions 8 to 28 and 1491 to 1508 on the Escherichia coli small-subunit rDNA sequence was used in this analysis. The procedures used for amplification and direct sequencing of PCR products have been described previously (21).

Phylogenetic analysis. The phylogenetic data described below were obtained (i) by using successive alignment and phylogeny procedures and (ii) by reinvestigating deep branching patterns after close relationships were determined (21). A neighbor-joining method (22) was used for the preliminary analysis; the resulting topologies were investigated further by using maximum-likelihood and maximum-parsimony methods. For the maximum-likelihood analyses we used the fdnaml program rewritten by G. J. Olsen (University of Illinois, Urbana) and compiled on a Hewlett-Packard model 700 workstation, while the maximumparsimony analyses were performed by using the PAUP program for Macintosh computers (23). The robustness of each topology was evaluated under maximumparsimony conditions through 100 bootstrap replications (heuristic search). Trees were constructed by using the njplot program for Macintosh computers developed by M. Gouy (URA 243, Centre National de la Recherche Scientifique, Université Claude Bernard, Lyon, France), which allows transformation of a formal tree representation (Newick's format) into MacDraw drawings. Only topologies that were found to be similar by all three methods were considered true trees. In recent theoretical work Kim has demonstrated that agreement of the results of all three methods which we used is a strong indication that the correct phylogeny has been determined (15).

Nucleotide sequence accession numbers. The nucleotide sequences which we determined have been deposited in the EMBL sequence database under accession numbers X84850 ( $N$. asteroides ATCC $\left.19247^{\mathrm{T}}\right), \mathrm{X} 84851(N$. asteroides ATCC 23824), X84852 (N. pseudobrasiliensis CIP 104598), X84854 (N. pseudobrasiliensis N249), X84855 (N. pseudobrasiliensis N649), X84856 (N. pseudobrasiliensis ATCC 51511), and X84857 (N. pseudobrasiliensis ATCC 51512 ${ }^{\mathrm{T}}$ ).

\section{RESULTS AND DISCUSSION}

As shown in Table 2, an analysis of the small-subunit rDNA sequences revealed that the levels of similarity were more than $99.4 \%$ when we compared the sequences of pairs of the five strains which we studied. General phylogenetic analyses revealed that these five strains belonged to a robust monophyletic unit that included all of the Nocardia and Rhodococcus equi strains belonging to one branch of the CMN group (20) whose sequences were available (Fig. 1). This finding was obtained with all of the methods which we used (neighbor joining, maximum likelihood, parsimony) and was supported by a boostrap value of $75 \%$. When the maximum-likelihood and parsimony methods were used, $R$. equi appeared to be a deep branch related to the genus Nocardia. In order to determine 


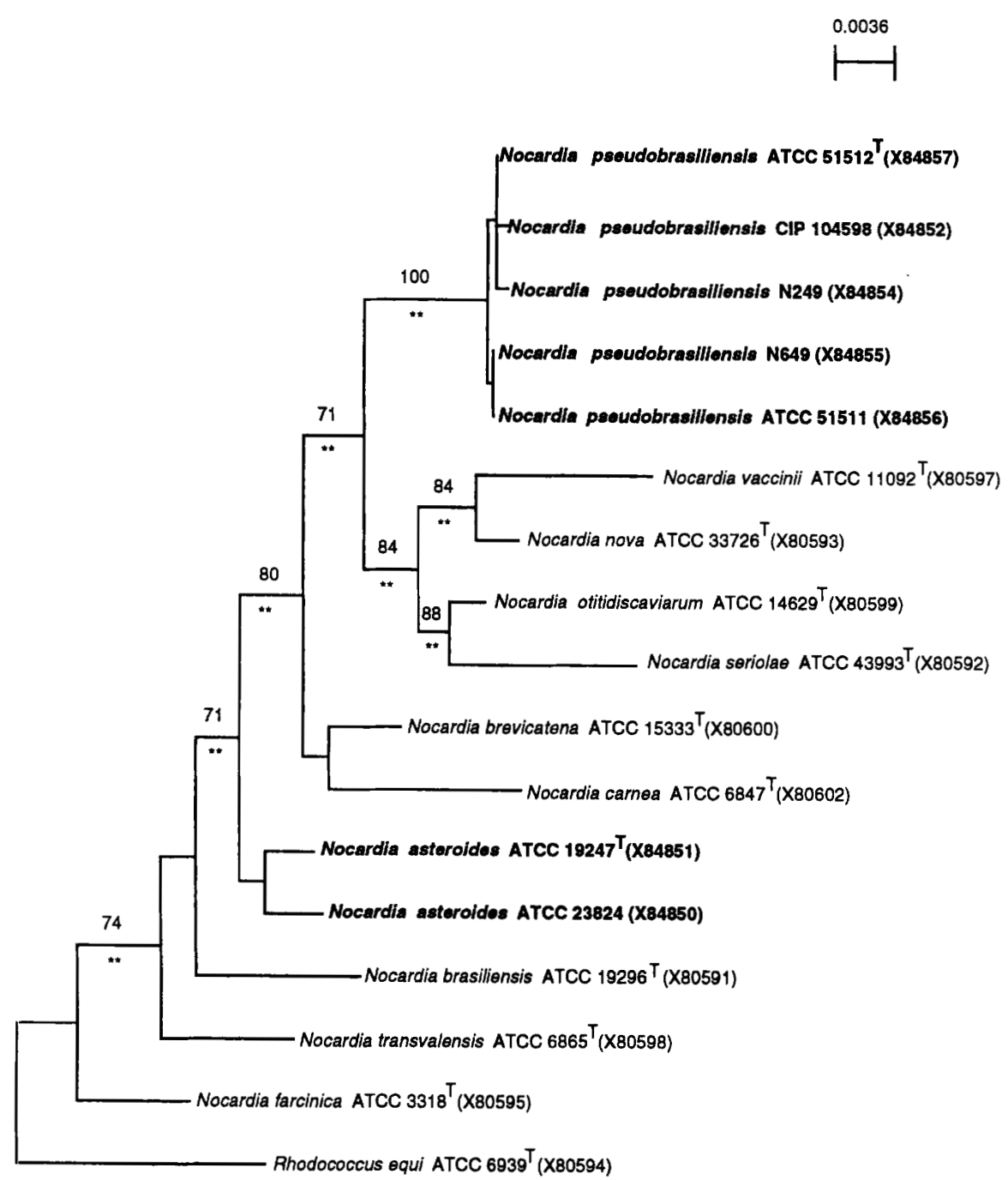

FIG. 2. Unrooted tree showing the phylogenetic position of $N$. pseudobrasiliensis within the genus Nocardia. The results of neighbor-joining, parsimony, and maximum-likelihood analyses were combined, as described in the legend to Fig. 1. The $N$. pseudobrasiliensis, N. vaccinii, $N$. nova, N. otitidiscaviarum, and N. seriolae strains formed a monophyletic unit that was identified by all three methods and by a bootstrap value of $71 \%$. The numbers in parentheses are nucleotide sequence accession numbers. The sequences of strains ATCC 51512 ${ }^{\mathrm{T}}$, CIP 104598, N249 (N249), N649 (N649), ATCC 51511, ATCC 19247 ${ }^{\mathrm{T}}$, and ATCC 23824 were determined in this study. The other sequences were obtained from the EMBL database.

the relationships among Nocardia species, we performed phylogenetic analyses with the five $N$. pseudobrasiliensis strains, all of the Nocardia species, and $R$. equi (as the outgroup). The topology obtained with the three phylogenetic methods clearly revealed that the type strain of $N$. brasiliensis and the new taxon should be separated (Fig. 2). All five N. pseudobrasiliensis strains formed a very tight monophyletic cluster with $N$. vaccinii, $N$. nova, $N$. otitidiscaviarum, and $N$. seriolae, as determined by all three methods (Fig. 2). In conclusion, the results of all of the phylogenetic analyses clearly demonstrated that the five $N$. pseudobrasiliensis strains belonged to the genus Nocardia on a single branch that was clearly distinct from $N$. brasiliensis and from all other Nocardia species.

The results of DNA-DNA hybridization experiments confirmed that the levels of similarity between strain ATCC $51512^{\mathrm{T}}$ DNA and the DNAs of strains ATCC 51511, N249, and N649 were high, and the $\Delta T_{m}$ values ranged from 0.5 to $3^{\circ} \mathrm{C}$ (Table 1). The level of relatedness between the DNAs of strains ATCC $51512^{\mathrm{T}}$ and CIP 104598 was lower $\left(60 \% ; \Delta T_{m}\right.$, $4.5^{\circ} \mathrm{C}$ ). However, strain CIP 104598 should probably be con- sidered a member of the same species as the other four strains on the basis of the criteria for defining a species established by the Ad Hoc Committee on Reconciliation of Approaches to Bacterial Systematics (28), the high levels of relatedness of the rDNA sequences, and the similar phenotypes. The fact that these strains represent a new Nocardia species was demonstrated by the finding that the levels of DNA relatedness with the type strain of $N$. brasiliensis (which has similar phenotypic characteristics) and the four other Nocardia species whose small-subunit rDNA sequences are most closely related (Fig. 2) (N. vaccinii, $N$. nova, $N$. otitidiscaviarum, and $N$. seriolae) were less than $15 \%$ (Table 1).

On the basis of chemotaxonomic characteristics the new species clearly belongs to the genus Nocardia. Its cell wall contained the components found in cell wall type IV bacteria (meso-diaminopimelic acid, arabinose, and galactose) and mycolic acids. As determined by HPLC, these mycolic acids were similar to those found in members of the genus Nocardia. Strain CIP 104598 had an HPLC mycolic acid ester pattern similar to the pattern described previously for strains N249, 
TABLE 3. Phenotypic characteristics used to differentiate N. pseudobrasiliensis from other Nocardia species $^{a}$

\begin{tabular}{|c|c|c|c|c|c|c|c|c|c|}
\hline Characteristic & 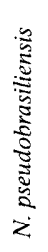 & 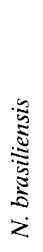 & 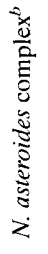 & 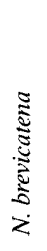 & $\begin{array}{l}\bar{\Xi} \\
\stackrel{\Xi}{\Xi} \\
z\end{array}$ & 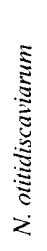 & 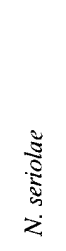 & 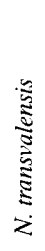 & 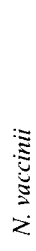 \\
\hline \multicolumn{10}{|l|}{ Decomposition of: } \\
\hline Adenine & + & - & - & - & - & - & - & $\mathrm{v}$ & - \\
\hline Casein & + & + & - & - & - & - & - & - & - \\
\hline Hypoxanthine & + & + & - & - & - & + & - & + & - \\
\hline Tyrosine & + & + & - & - & - & - & - & - & - \\
\hline Xanthine & - & - & - & - & - & + & - & $\mathrm{v}$ & - \\
\hline \multicolumn{10}{|l|}{$\begin{array}{l}\text { Acid produced } \\
\text { from: }\end{array}$} \\
\hline Ribitol & - & - & - & - & -- & - & - & + & - \\
\hline L-Arabinose & - & - & - & - & - & $\mathrm{v}$ & - & - & + \\
\hline Erythritol & - & - & - & - & - & - & - & + & - \\
\hline D-Galactose & + & + & $\mathrm{v}$ & - & + & - & - & + & t \\
\hline D-Glucose & + & + & + & - & + & + & + & + & + \\
\hline Inositol & + & + & - & - & $\mathrm{v}$ & + & - & $\mathrm{v}$ & $\mathrm{v}$ \\
\hline Mannitol & + & + & - & - & + & $v$ & - & $v$ & - \\
\hline L-Rhamnose & - & - & v & - & - & - & - & - & $\mathrm{v}$ \\
\hline D-Glucitol & - & - & - & - & + & - & - & $\mathrm{v}$ & $\mathrm{v}$ \\
\hline Trehalose & + & + & $\mathrm{v}$ & + & + & $\mathrm{v}$ & - & $\mathrm{v}$ & $\mathrm{v}$ \\
\hline \multicolumn{10}{|l|}{ Production of: } \\
\hline Nitrate reductase & - & + & + & - & + & + & ND & + & + \\
\hline Urease & + & + & + & - & - & + & - & + & + \\
\hline
\end{tabular}

"Data from references 10 and $24 .+, 90 \%$ or more of the strains are positive ,$- 10 \%$ or less of the strains are positive; $v, 11$ to $89 \%$ of the strains are positive ND, not determined.

${ }^{b}$ The $N$. asteroides complex includes $N$. nova, $N$. farcinica, and $N$. asteroides sensu stricto, three validly described species whose physiological characteristics are similar.

N649, ATCC 51511, and ATCC $51512^{\mathrm{T}}$ (25). Two early peaks in this pattern (peaks A and B) were not found in any of the $N$. brasiliensis sensu stricto strains. All of the strains also contained tetrahydrogenated menaquinones with eight isoprene units as their major isoprenologs, but a distinction between MK- $8\left(\mathrm{H}_{4}\right)$ and MK- $8\left(\mathrm{H}_{4, \omega-c y c l}\right)$ was not possible because of the experimental design of the HPLC method used. However, all of the strains produced the same HPLC menaquinone pattern as $N$. asteroides ATCC $19247^{\mathrm{T}}$, which contains MK- $8\left(\mathrm{H}_{4}\right.$ $\omega$-cycl $)$. Considering all of the data, $\mathrm{MK}-8\left(\mathrm{H}_{4, \omega-c y c l}\right)$ is probably present in the strains which we examined, but this remains to be proved by adequate techniques (12). All of these chemotaxonomic characteristics, as well as the $\mathrm{G}+\mathrm{C}$ contents of the DNAs (Table 1), are consistent with the description of the genus Nocardia $(8,10)$.

The sites of isolation, phenotypic characteristics, and patterns of susceptibility to antibiotics of strain CIP 104598 and the other strains belonging to the new taxon defined by Wallace et al. were similar (25). Finally, the five strains which we studied were similar to $N$. brasiliensis in some characteristics (decomposition of casein, tyrosine, xanthine, and hypoxanthine) but not in others (decomposition of adenine and nitrate reductase activity) (Table 3 ). These strains were susceptible to ciprofloxacin and resistant to minocycline.

In conclusion, the results of physiological tests, tests to determine susceptibility to antibiotics, mycolic acid analyses, and genomic analyses (DNA base composition determinations, DNA-DNA hybridization tests, and phylogenetic analyses of small-subunit rDNA sequences) indicated that the five invasive isolates which we studied (four strains isolated in the United States and one strain isolated in France) are members of a new Nocardia species, for which we propose the name Nocardia pseudobrasiliensis.

Description of Nocardia pseudobrasiliensis sp. nov. Nocardia pseudobrasiliensis (pseu.do.bra.si.li.en'sis. Gr. adj. pseudes, false; M.L. adj. brasiliensis, pertaining to Brazil, a specific epithet; M.L. adj. pseudobrasiliensis, a false brasiliensis). The description below is based on data from this study and the study of Wallace et al. (25).

Strains are orange-tan to $\tan$. The cells have typical Nocardia micromorphology; branched vegetative hyphae (diameter, 0.5 to $1.2 \mu \mathrm{m}$ ) fragment into bacteroid or rod-shaped to coccoid, nonmotile elements. Aerial mycelium is produced. Endospores, sporangia, scerotia, and synnemata are not formed. No soluble pigment is produced. The cells are strictly aerobic and have an oxidative type of metabolism. They exhibit catalase, alkaline phosphatase, butyrate esterase, caprylate esterase, leucine arylamidase, acid phosphatase, phosphohydrolase, $\beta$ galactosidase, $\alpha$-glucosidase, $\beta$-glucosidase, and $N$-acetyl- $\beta$ glucosaminidase activities.

Cells are gram positive and acid fast or partially acid fast as determined by the modified Kinyoun method (1\% sulfuric acid decolorization), but they are not acid fast as determined by the standard Kinyoun method. Growth occurs at $37^{\circ} \mathrm{C}$ but not at 10 or $43^{\circ} \mathrm{C}$ after 2 weeks. Cells are resistant to lysozyme.

Adenine, casein, hypoxanthine, and tyrosine are decomposed, but xanthine is not decomposed. Urease is produced, but nitrate reductase is not produced. Acid is produced from D-galactose, D-glucose, glycerol, inositol, D-mannitol, D-mannose, trehalose, and citrate, but not from ribitol, L-arabinose, cellobiose, erythritol, lactose, maltose, melibiose, melezitose, raffinose, L-rhamnose, D-glucitol, and D-xylose.

The $\mathrm{G}+\mathrm{C}$ content of the DNA is 67 to $68 \mathrm{~mol} \%$, as determined by the capillary electrophoresis procedure (19).

The cell wall contains meso-diaminopimelic acid, arabinose, and galactose. Nocardomycolic acids are present. As determined by HPLC, the mycolic acid patterns include two early peaks that are not found in any $N$. brasiliensis sensu stricto pattern. Contains predominant menaquinones similar to those in $N$. asteroides ATCC $19247^{\mathrm{T}}$ as determined by an HPLC method (24).

The type strain is strain ATCC 51512 (= CIP 104600). This organism was isolated from a leg abscess on a patient suffering from ulcerative colitis. The $\mathrm{G}+\mathrm{C}$ content of its DNA is 67.1 mol\%.

\section{ACKNOWLEDGMENTS}

This work was supported by the Centre National de la Recherche Scientifique, by bioMérieux S.A., and by a fellowship from MRE to R.R.

\section{REFERENCES}

1. Beaman, B. L., P. Boiron, L. Beaman, G. H. Brownell, K. Schaal, and M. E. Gombert. 1992. Nocardia and nocardiosis. J. Med. Vet. Mycol. 30(Suppl. I): 317-331.

2. Beaman, B. L., J. Burnside, B. Edwards, and W. Causey. 1976. Nocardial infections in the United States, 1972-1974. J. Infect. Dis, 134:286-289.

3. Blackall, L. L., S. C. Barker, and P. Hugenholtz. 1995. Phylogenetic analysis and taxonomic history of Nocardia pinensis and Nocardia amarae. Syst. Appl. Microbiol. 17:519-526.

4. Boiron, P., F. Provost, G. Chevrier, and B. Dupont. 1992. Review of nocardial infections in France 1987 to 1990. Eur. J. Clin. Microbiol. Infect. Dis. 11: 709-714.

5. Carlotti, A., H. Meugnier, M. T. Pommier, J. Villard, and J. Freney. 1993. Chemotaxonomy and molecular taxonomy of some coryneform isolates. Zentralbl. Bakteriol. Parasitenkd. Infektionskr. Hyg. Abt. 1 Orig. 278:23-33.

6. Crosa, J. H., D. J. Brenner, and S. Falkow. 1973. Use of a single-strandspecific nuclease for analysis of bacterial and plasmid deoxyribonucleic acid 
homo- and heteroduplexes. J. Bacteriol. 115:904-911.

7. Gehrke, C. W., R. A. McCune, A. Gamma-Sosa, M. Erlich, and K. C. Kuo. 1984. Quantitative reversed-phase high performance liquid chromatography of major and modified nucleoside in DNA. J. Chromatogr. 301:199-219.

8. Goodfellow, M. 1992. The family Nocardiaceae, p. 1188-1213. In A. Balows, H. G. Trüper, M. Dworkin, W. Harder, and K.-H. Schleifer (ed.), The prokaryotes, 2nd ed., vol. 2. Springer-Verlag, New York.

9. Goodfellow, M., J. Chun, S. Stubbs, and A. S. Tobili. 1994. Transfer of Nocardia amarae Lechevalier and Lechevalier 1974 to the genus Gordona as Gordona amarae comb. nov. Lett. Appl. Microbiol. 19:401-405.

10. Goodfellow, M., and M. P. Lechevalier. 1989. Genus Nocardia Trevisan 1889, $9^{\mathrm{AL}}$, p. 2350-2361. In S. T. Williams, M. E. Sharpe, and J. G. Holt (ed.), Bergey's manual of systematic bacteriology, vol. 4. The Williams and Wilkins Co., Baltimore.

11. Grimont, P. A. D., M. Y. Popoff, F. Grimont, C. Coynault, and M. Lemelin. 1980. Reproducibility and correlation study of three deoxyribonucleic acid hybridization procedures. Curr. Microbiol. 4:325-330.

12. Howarth, O. W., E. Grund, R. M. Kroppenstedt, and M. D. Collins. 1986. Structural determination of a new naturally occurring cyclic vitamin K. Biochem. Biophys. Res. Commun. 140:916-923.

13. Jones, K. L. 1949. Fresh isolates of actinomycetes in which the presence of sporogenous aerial mycelia is a fluctuating characteristic. J. Bacteriol. 57: $141-145$.

14. Jost, K. C., and D. Dunbar. 1992. Automated identification of mycobacteria by high-performance liquid chromatography using computer-aided pattern recognition algorithms, abstr. U-69, p. 177. In Abstracts of the 92nd General Meeting of the American Society for Microbiology 1992. American Society for Microbiology, Washington, D.C.

15. Kim, J. 1993. Improving the accuracy of phylogenetic estimation by combining different methods. Syst. Biol. 42:331-340.

16. Klatte, S., F. A. Rainey, and M. Kroppenstedt. 1994. Transfer of Rhodococcus aichiensis Tsukamura 1982 and Nocardia amarae Lechevalier and Lechevalier 1974 to the genus Gordona as Gordona aichiensis comb. nov. and Gordona amarae comb. nov. Int. J. Syst. Bacteriol. 44:769-773.

17. Page, A. C. P., P. Gale, H. Wallick, R. B. Walton, L. E. McDaniel, H. B. Woodruff, and K. Folkers. 1960. Isolation of coenzyme Q10 from bacterial fermentation. Arch. Biochem. Biophys. 89:318-321.

18. Riegel, P., D. De Briel, G. Prévost, F. Jehl, and H. Monteil. 1994. Genomic diversity among Corynebacterium jeikeium strains and comparison with biochemical characteristics and antimicrobial susceptibilities. J. Clin. Microbiol. 32:1860-1865.

19. Riegel, P., R. Ruimy, D. De Briel, G. Prévost, F. Jehl, F. Bimet, R. Christen and H. Monteil. 1995. Corynebacterium seminale sp. nov., a new species associated with genital infections in male patients. J. Clin. Microbiol. 33: 2244-2249

20. Ruimy, R., P. Boiron, V. Boivin, and R. Christen. 1994. A phylogeny of the genus Nocardia deduced from the analysis of small-subunit ribosomal DNA sequences, including transfer of Nocardia amarae to the genus Gordona as Gordona amarae comb. nov. FEMS Microbiol. Lett. 123:261-268.

21. Ruimy, R., V. Breittmayer, P. Elbaze, B. Lafay, O. Boussemart, M. Gauthier, and R. Christen. 1994. Phylogenetic analysis and assessment of the genera Vibrio, Photobacterium, Aeromonas, and Plesiomonas deduced from the small-subunit rRNA sequences. Int. J. Syst. Bacteriol. 44:416-426.

22. Saitou, N., and M. Nei. 1987. The neighbor-joining method: a new method for reconstructing phylogenetic trees. Mol. Biol. Evol. 4:406-425.

23. Swofford, D. 1990. PAUP: phylogenetic analysis using parsimony, version 3.0 Illinois Natural History Survey, Champaign.

24. Tamakoa, J., Y. Katayama-Fujimura, and H. Kuraishi. 1983. Analysis of bacterial menaquinone mixtures by high performance liquid chromatography. J. Appl. Bacteriol. 54:31-36.

25. Wallace, R. J., Jr., B. A. Brown, Z. Blacklock, R. Ulrich, K. Jost, J. M. Brown, M. M. McNeil, G. Onyi, V. A. Steingrube, and J. Gibson. 1995. New Nocardia taxon among isolates of Nocardia brasiliensis associated with invasive disease. J. Clin. Microbiol. 33:1528-1533.

26. Wallace, R. J., Jr., B. A. Brown, M. Tsukamura, J. M. Brown, and G. O. Onyi. 1991. Clinical and laboratory features of Nocardia nova. J. Clin. Microbiol. 29:2407-2411.

27. Wallace, R. J., Jr., M. Tsukamura, B. A. Brown, J. Brown, V. A. Steingrube, Y. Zhang, and D. R. Nash. 1990. Cefotaxime-resistant Nocardia asteroides strains are isolates of the controversial species Nocardia farcinica. J. Clin. Microbiol. 28:2726-2732.

28. Wayne, L. G., D. J. Brenner, R. R. Colwell, P. A. D. Grimont, O. Kandler, M. I. Krichevsky, L. H. Moore, W. E. C. Moore, R. G. E. Murray, E. Stackebrandt, M. P. Starr, and H. G. Trüper. 1987. Report of the Ad Hoc Committee on Reconciliation of Approaches to Bacterial Systematics. Int. J. Syst. Bacteriol. 37:463-464. 